\title{
In vitro fertilization: A private matter becomes public
}

Previously published at www.cmaj.ca on Aug. 31, 2009.

$\mathrm{F}$ or infertile couples, the cost of becoming pregnant is largely a private matter in most of Canada. However, the cost of treating complications from multiple births that often occur following advanced fertility treatments is a public one. This paradox is at the heart of the reason why we believe that in vitro fertilization and intracytoplasmic sperm injection should be covered under medicare.

In Canada, the overall live birth rate with in vitro fertilization is $27 \%$ per cycle, which is higher than that of natural conception. ${ }^{1}$ However, as in vitro technology has improved, the number of multiple births has increased. This is because our current policy encourages women to have multiple embryos transfered at once, rather than costly multiple rounds of single-embryo transfer. Understandably, women want to maximize their chances of getting pregnant.

Infertility treatment is expensive. On average, 1 round of ovarian stimulation and the associated medications cost about $\$ 10000$, but the cost can climb to $\$ 15000-\$ 20000$ for women who do not respond well to the medication and thus require higher doses. At such prices, almost $59 \%$ of couples would prefer twins ${ }^{2}$ if transferring 2 embryos increases their chance of pregnancy. ${ }^{3}$

Multiple gestational pregnancies pose higher health risks for both mother and child. Perinatal mortality is 4-fold higher among twins and 6-9-fold higher among triplets. Complications such as cerebral palsy are 3-7 times more common among twins and 10 times more common among triplets. ${ }^{4}$ When these complications occur, it is the public health care system that bears the cost while the parents and children bear the grief.

The refusal by most provincial governments to pay for infertility treatment is driving higher rates of multiple births and the resultant complications of prematurity. In addition, such policies lack a full analysis of cost-effectiveness, ${ }^{5}$ thereby costing taxpayers unnecessary dollars and costing mothers and babies their health. (In Ontario, the province will cover in vitro fertilization only for women with blocked fallopian tubes - a discriminatory practice that has prompted an expert panel to review coverage of the costs of both in vitro fertilization and adoption).

An equity issue also exists. Under our current system, access to advanced reproductive technology is the purview of those with the socio-economic means to afford it. ${ }^{6}$ Treatment occurs primarily in private clinics where profit motives drive both the costs and quality of care.

We do not have to look far for a remedy. Quebec has recently introduced legislation that will see its health insurance system pay for in vitro fertilization. Finland's decision to finance single-embryo transfer has resulted in a decrease in the proportion of multiple births after in vitro fertilization, down to $14 \%$ in 2002 from $24 \%$ in 1996, with an unchanged live birth rate. ${ }^{7}$ Belgium and Sweden have reported similar results from financing single-embryo transfer. ${ }^{8,9}$

These international examples suggest that the easiest way to reduce the costs of complications related to assisted reproductive technology is to extend the coverage of universal care.
Attempts to reduce the number of multiple births by simply advising private clinics on the appropriate number of embryos to transfer has failed to optimize the birth of healthy singletons. The Society of Obstetricians and Gynecologists of Canada and the board of the Canadian Fertility and Andrology Society issued that guideline in 2006. ${ }^{10}$ These recommendations have not resulted in a noteworthy decrease in the number of multiple gestational pregnancies in Canada.

It is time to stop driving women toward practices that worsen health outcomes and are short-sighted from a health care cost perspective. All Canadian provinces should join Quebec in funding in vitro fertilization and intracytoplasmic sperm injection. In conjunction with the decision by Quebec's government, clinics in that province have agreed to strive toward ensuring that no more than a small percentage of their patients undergo multiple gestational pregnancies. A similar orchestrated, co-operative approach across the country is needed to improve health outcomes for Canadian women undergoing treatment with advanced reproductive technology and their children.

\section{Renda Bouzayen MD}

Division Head, Reproductive Endocrine and Infertility

Dalhousie University

\section{Laura Eggertson BA}

News Correspondent, CMAJ

With the Editorial-Writing Team (Paul C. Hébert MD MHSc, Matthew B. Stanbrook MD PhD, Ken Flegel MDCM MSc, Noni MacDonald MD MSc)

Competing Interests: None declared for Renda Bouzayen. See www.cmaj .ca/misc/edboard.shtml for the Editorial-Writing Team's statements.

Cite as CMAJ 2009. DOI:10.1503/cmaj.091344

\section{REFERENCES}

1. Canadian Fertility and Andrology Society. Human assisted reproduction 2008 live birth rates. Montréal (QC): The Society; 2008. Available: www.cfasonline .ca/index.php?option=com_content $\&$ view=article \&id=211\%3Ahuman-assisted -reproduction-2008-live-birth-rates-for-canada\&catid=929\%3Apress-releases\&Itemid $=460($ accessed 2009 Jul. 20)

2. Højgaard A, Ottosen LD, Kesmodel U, et al. Patient attitudes towards twin pregnancies and single embryo transfer - a questionnaire study. Hum Reprod 2007;22:2673-8.

3. Twisk M, van der Veen F, Repping S, et al. Preferences of subfertile women regarding elective single embryo transfer: additional in vitro fertilization cycles are acceptable, lower pregnancy rates are not. Fertil Steril 2007;88:1006-9.

4. Petterson B, Nelson KB, Watson L, et al. Twins, triplets and cerebral palsy in births in Western Australia in the 1980s. BMJ 1993;307:1239-43.

5. Fiddelers AA, Severens JL, Dirksen CD, et al. Economic evaluations of singleversus double-embryo transfer in IVF. Hum Reprod Update 2007;13:5-13.

6. Hughes E. Access to effective fertility care in Canada. J Obstet Gynaecol Can 2008;30:389-90.

7. Tiitinen A, Hydén-Granskog C, Gissler M. What is the most relevant standard of success in assisted reproduction? The value of cryopreservation on cumulative pregnancy rates per single oocyte retrieval should not be forgotten. Hum Reprod 2004;19:2439-41.

8. Gordts S, Campo R, Puttemans P, et al. Belgian legislation and the effect of elective single embryo transfer on IVF outcome. Reprod Biomed Online 2005;10:436-41.

9. Karlström PO, Bergh C. Reducing the number of embryos transferred in Swedenimpact on delivery and multiple birth rates. Hum Reprod 2007;22:2202-7.

10. Joint SOGC-CFAS. Guidelines for the number of embryos to transfer following in vitro fertilization: No. 182, September 2006. Int J Gynaecol Obstet 2008;102:203-16. 